\title{
ORIENTASI KEWIRAUSAHAAN, \\ ORIENTASI PASAR, DAN KINERJA PERUSAHAAN
}

\author{
GABRIELLE VANIA SETIADI \\ Fakultas Bisnis dan Ekonomi, Universitas Surabaya
}

\begin{abstract}
ENTREPRENEURIAL ORIENTATION
Entrepreneurial Orientation atau Orientasi Kewirausahaan dapat dimanifestasikan dalam sistem hubungan dan makna yang saling terkait dari elemen kewirausahaan, yang terdiri atas pengambilan risiko, proaktif, dan inovatif. (Gupta, 2015). Orientasi kewirausahaan merupakan sebuah konsep multidimensi, yang berarti gaya strategis di tingkat perusahaan dan orientasi strategis dalam hal pengambilan keputusan perusahaan dan praktek kewiraswastaan. (Lan \& Wu, 2010). EO juga menyiratkan orientasi strategis perusahaan untuk memasuki pasar baru dengan memberikan produk dan layanan baru. (Khalili, Nejadhussein, \& Fazel, 2013).
\end{abstract}

Analisis (Franco \& Haase, 2013) menunjukkan bahwa kapasitas inovatif dan kemampuan kolektif sebuah perusahaan cenderung menunjukkan kewirausahaan yang bersifat kolaboratif. Inovatif dapat terlihat dari cara seseorang mengadopsi dan memodifikasi teknologi baru yang ada untuk memenuhi kebutuhan kliennya dan secara aktif bekerja untuk meningkatkan proses internalnya serta keinginan untuk melakukan upaya untuk melampaui teknologi dan praktik yang ada saat ini. (Vora, Vora, \& Polley, 2012). Inovatif juga berarti mengembangkan proses baru serta mengenali dan mengembangkan pasar baru (Wolff, Pett, \& Ring, 2015).

Dimensi proaktif berperan penting dalam kemampuan perusahaan untuk mengidentifikasi tren pasar (Altinay \& Wang, 2011). Proaktif 
mengacu pada kemampuan perusahaan untuk meramalkan perubahan pasar, mengendalikan lingkungan, dan mengadopsi teknik-teknik baru dalam praktik di masa depan, sehingga memungkinkan keuntungan penggerak pertama (Lan \& Wu, 2010; Pratono, 2016). Proaktifitas perusahaan menentukan sikap pengembangan produk baru terhadap penciptaan gagasan inovatif dan mewujudkan ide-ide menjadi kenyataan. (Wong, 2014)

Pengambilan risiko berbeda dari proaktif, karena dimensi ini mencerminkan kesediaan untuk menggunakan pendekatan baru, untuk merambah ke sesuatu yang tidak diketahui tanpa mengetahui kemungkinan keberhasilan. (Caseiro \& Coelho, 2018). Pengambilan risiko dianggap sebagai mengeksploitasi peluang pasar yang berisiko dan bereksperimen dengan produk dan layanan baru. (Wolff, Pett, \& Ring, 2015). Pengambilan risiko sebaiknya dilakukan dengan menyeimbangkan perilaku pengambilan risiko maupun perilaku menghindari risiko. (Vora, Vora, \& Polley, 2012; Pratono, 2018).

Competitive aggressiveness dapat meningkatkan pangsa pasar dan kinerja dengan cara membuat serangan agresif untuk mengancam setiap pesaing yang berpotensial. (Jia, Wang, Zhao, \& Yu, 2014). Competitive aggressiveness ditunjukkan dari tindakan yang berusaha menghindari konfrontasi langsung dengan pesaing. (Vora, Vora, \& Polley, 2012).

Autonomy adalah kemampuan dan kemauan individu atau tim untuk mencari dan mengeksplorasi peluang baru. (Jia, Wang, Zhao, \& Yu, 2014). Otonomi kewirausahaan memungkinkan perusahaan untuk secara yakin mengartikulasikan mengapa produk menawarkan nilai yang lebih besar daripada pesaing melalui kemampuan penetapan harga (Pratono, Ratih, \& Arshad, 2018).

\section{KINERJA PERUSAHAAN}

Definisi kinerja perusahaan mencakup berbagai ukuran produktivitas seperti biaya produksi, pertumbuhan produktivitas, atau ukuran profitabilitas seperti laba atas ekuitas (ROE), laba atas aset (ROA), dan rasio pasar terhadap bookvalue (Chaudhuri, Kumbhakar, \& Sundaram, 2016). Suatu perusahaan memiliki beberapa fungsi bisnis, antara lain $R$ \& $D$, produksi, pemasaran, dan penjualan, yang berkontribusi terhadap 
kinerja perusahaan secara keseluruhan (Rezaei \& Ortt, 2018). Dengan kata lain, kinerja perusahaan dapat diartikan sebagai sebuah konsep yang mencakup berbagai dimensi seperti kinerja operasional dan manajemen dari sebuah perusahaan beserta kegiatannya (Tseng \& Liao, 2015).

Firm Performance dapat berfungsi sebagai salah satu variabel penting dalam pengambilan keputusan perusahaan, terutama dalam menentukan strategi perusahaan (Tarus \& Aime, 2014). Menurut (Lee \& Roh, 2012), FP terbagi atas financial performance dan market-based performance. Financial performance mencakup ROA dan ROE sedangkan market-based performance mencakup pertumbuhan pasar. Financial performance berkaitan dengan faktor ekonomi, seperti profitabilitas dan pertumbuhan penjualan (laba atas investasi, laba atas penjualan dan laba atas ekuitas) (Zehir, Can, \& Karaboga, 2015). Nonfinancial performance dianggap lebih luas dan lebih praktis karena memperhitungkan faktor-faktor utama yang mungkin mempengaruhi financial performance (Othman, Rahman, Sundram, \& Bhatti, 2015).

Kinerja dapat diukur secara obyektif atau subjektif, menyangkut nilai absolut dan relatif terhadap pesaing serta harapan di perusahaan (Pehrsson, 2016). Ada beberapa kombinasi dimana keberadaan beberapa ketentuan dan tidak adanya orang lain akan mengarah pada kinerja perusahaan (Madanoglua, Kizildagb, \& Ozdemir, 2018). Kinerja perusahaan dapat disebabkan oleh faktor CEO yang sulit dikembangkan secara eksternal, seperti kecerdasan/ kepribadian/ pengetahuan/ keterampilan yang tidak diajarkan (Lindorff \& Jonson, 2013). Kinerja perusahaan juga dapat diukur dalam hal kinerja saham jangka pendek dan jangka panjang serta kinerja operasi yang terkait dengan pengumuman (Chen, Lin, \& Tsa, 2018).

EO-FP

Peneliti sering melihat EO sebagai variabel independen yang menciptakan atau mempertahankan kinerja perusahaan (Lee \& Chu, 2017). Beberapa studi telah menunjukkan bahwa EO berpengaruh terhadap FP. Menurut (Shan, Song, \& Ju, 2016), tiga dari lima variabel EO (Inovasi, Otonomi, dan Pengambilan Risiko) memiliki pengaruh signifikan terhadap kinerja perusahaan. Studi milik (Zehir, Can, \& Karaboga, 2015) juga menyatakan bahwa tiga dimensi EO (proaktif, 
inovatif dan otonomi) memiliki pengaruh yang signifikan terhadap hubungan EO-FP. (Pratono, Ratih, \& Arshad, 2018) juga menyatakan bahwa otonomi memiliki dampak langsung, positif, dan signifikan terhadap kinerja perusahaan.

Entebang, Harrison, \& Cyril (2010) memperdebatkan bahwa jenis inovasi yang lebih substansial dan radikal cenderung memiliki dampak yang signifikan terhadap kinerja organisasi secara keseluruhan, sementara inovasi inkremental memiliki dampak yang rendah dan jangka pendek karena inovasi semacam itu biasanya berkonsentrasi pada inisiatif atau kegiatan perbaikan kecil atau proses. (Morgan, Anokhin, \& Wincent, 2016) menyatakan bahwa dimensi pengambilan risiko dari EO juga memiliki relevansi dengan FP, karena perusahaan akan mengambil lebih banyak risiko dalam berhubungan dengan perusahaan lain untuk memaksimalkan keunggulan kompetitif mereka sendiri.

EO berhubungan positif dengan kinerja perusahaan dan hubungan positif tersebut dapat ditingkatkan ketika kepemilikan keluarga dikombinasikan dengan manajemen keluarga dan kontrol keluarga (Lee \& Chu, 2017). Menurut (Cowden, Tang, \& Bendickson, 2016), hubungan antara EO-FP sudah mapan. Ketika perusahaan matang, hubungan antara EO dan kinerja perusahaan menjadi lebih kuat ketika spesifisitas aset masih relatif rendah, ketika pendiri memiliki masa kerja yang lebih lama dengan perusahaan, dan ketika pengaruh perusahaan terhadap budaya mereka masih relatif rendah. Dengan demikian, bila orientasi kewirausahaan bekerja secara efektif dapat menjadi penentu yang baik untuk mencapai sebuah kinerja perusahaan yang memuaskan (Li, Huang, \& Tsai, 2009).

Davis, Bell, Payne, \& Kreiser (2010) menyatakan bahwa manajer dengan orientasi kewirausahaan yang tinggi akan memiliki dampak positif terhadap kinerja perusahaan. Tiga dimensi EO yaitu inovasi, proaktif, dan pengambilan risiko memungkinkan seseorang untuk mengidentifikasi dan memanfaatkan peluang yang muncul dan membangun strategi kewirausahaan yang mengarah ke pertumbuhan perusahaan. Kinerja perusahaan dijelaskan oleh konfigurasi EO dalam kombinasi antara permusuhan lingkungan dengan pertumbuhan pasar (Shirokova, Bogatyreva, \& Belia, 2016). Oleh karena itu, perusahaan yang melakukan tindakan yang mewakili EO dapat merundingkan 
dinamika lingkungan yang lebih berhasil dan menghasilkan tingkat kinerja perusahaan yang lebih tinggi (Wolff, Pett, \& Ring, 2015).

\section{Market Orientation}

Market Orientation mencerminkan sejauh mana perencanaan pasar perusahaan didorong oleh pelanggan dan intelijen pesaing (MontielCampos, 2018). MO menyediakan pengaruh yang efektif untuk mencapai kegiatan wirausaha, dengan cara berusaha untuk memuaskan kebutuhan pelanggan, mengejar ekspansi pasar, dan memanfaatkan peluang yang muncul (Grinstein, 2008). MO membutuhkan komitmen yang kuat agar serangkaian proses, keyakinan, dan nilai-nilai perusahaan dapat tercerminkan (Muecke \& Hofer, 2015)

MO membantu perusahaan melacak dan menanggapi perubahan kebutuhan pelanggan (Shoham, Rose, \& Kropp, 2005). Orientasi pasar memiliki tiga dimensi,yaitu customer orientation, competitor orientation, dan interfunctional coordination (Liu, Ke, Wei, \& Hua, 2013). Customer orientation berbicara tentang target pembeli agar dapat menciptakan nilai superior; Competitor orientation mencakup tentang memahami keunggulan dan kelemahan jangka pendek maupun jangka panjang dari pesaing; dan interfunctional coordination mencakup pemanfaatan sumber daya perusahaan yang terkoordinasi untuk menciptakan nilai unggul bagi pelanggan sasaran (Ngai \& Ellis, 1998).

Hubungan antara EO dan MO menunjukkan fokus pasar mencakup komponen EO yang signifikan. Maka, dimensi EO (inovasi, pengambilan risiko dan proaktif) merespon perubahan pasar dan dipengaruhi oleh pasar itu sendiri (Todorovic \& Ma, 2008). Orientasi kewirausahaan berhubungan positif dengan orientasi pasar, sehingga semakin tinggi tingkat kewirausahaan, maka semakin tinggi pula derajat orientasi pasar, dan sebaliknya (Benito, Benito, \& Gallego, 2009).

EO memiliki hubungan yang signifikan dengan MO, contohnya perusahaan yang proaktif akan mencapai target, bergerak lebih cepat untuk mempertahankan keuntungan, dan memanfaatkan peluang pasar untuk hasil yang lebih tinggi (Amin, Thurasamy, \& Aldakh, 2016). (Matear, Osborne, Garrett, \& Gray, 2002) mengatakan bahwa perusahaan yang lebih berorientasi pasar, kegiatan inovasinya akan 
memberikan keterlibatan yang lebih besar kepada kinerja perusahaan. Dengan kata lain, MO dan EO berfungsi sebagai pendorong penting dalam meningkatkan kinerja perusahaan ritel kecil (Kajalo \& Lindblom, 2015).

Orientasi pasar telah diakui sebagai strategi bisnis yang sukses oleh para akademisi dan praktisi (Chao \& Spillan, 2010). MO berpengaruh positif terhadap kinerja perusahaan (Tseng \& Liao, 2015). Berorientasi pasar lebih penting untuk meningkatkan probabilitas keberhasilan kegiatan wirausaha perusahaan dan meningkatkan kinerja perusahaan (Mahrous \& Genedy, 2018). MO memiliki korelasi yang kuat dan signifikan dengan kinerja perusahaan secara keseluruhan (Kocak, Carsrud, \& Oflazoglu, 2017). Oleh karena itu, sinergi antara EO dan MO menentukan kinerja perusahaan (Montiel-Campos, 2018)

\section{Referensi}

Altinay, L., \& Wang, C. L. (2011). The influence of an entrepreneur's socio-cultural characteristics on the entrepreneurial orientation of small firms. Journal of Small Business and Enterprise Development, Vol. 18 pp.673-694, https://doi.org/10.1108/14626001111179749.

Amin, M., Thurasamy, R., \& Aldakh, A. M. (2016). The effect of market orientation as a mediating variable in the relationship between entrepreneurial orientation and SMEs performance. Nankai Business Review International, Vol. 7 Issue: 1, pp.39-59, https://doi.org/10.1108/NBRI-08-2015-0019.

Benito, Ó. G., Benito, J. G., \& Gallego, P. A. (2009). Role of entrepreneurship and market orientation in firms' success. European Journal of Marketing, Vol. 43 Issue: 3/4, pp.500-522, https://doi.org/10.1108/03090560910935550.

Caseiro, N., \& Coelho, A. (2018). Business intelligence and competitiveness: the mediating role of entrepreneurial orientation. Competitiveness Review: An International Business Journal, Vol. 28, Issue: 2, pp.213-226, https://doi.org/10.1108/CR-09-2016-0054.

Chao, M. C.-H., \& Spillan, J. E. (2010). The journey from market orientation to firm performance: A comparative study of US and Taiwanese SMEs. Management Research Review, Vol. 33 Issue: 5, pp.472-483, https://doi.org/10.1108/01409171011041901. 
Chaudhuri, K., Kumbhakar, S. C., \& Sundaram, L. (2016). Estimation of firm performance from a MIMIC model. European Journal of Operational Research, 298-307.

Chen, S.-S., Lin, C.-Y., \& Tsa, Y.-C. (2018). New product strategies and firm performance: CEO optimism. International Review of Economics and Finance, International Review of Economics and Finance 55 (2018) 37-53.

Cowden, B. J., Tang, J., \& Bendickson, J. (2016). The maturing of entrepreneurial firms: Entrepreneurial orientation, firm performance, and administrative heritage. New England Journal of Entrepreneurship, Vol. 19 Issue: 2, pp.42-53 https://doi.org/10.1108/NEJE-19-02-2016B004.

Davis, J. L., Bell, R. G., Payne, G. T., \& Kreiser, P. M. (2010). Entrepreneurial Orientation and Firm Performance: The Moderating Role of Managerial Power. American Journal of Business, Vol. 25 Issue: 2, pp.41-54 https://doi.org/10.1108/19355181201000009.

Entebang, H., Harrison, R. T., \& Cyril, E. (2010). Entrepreneurial orientation of public enterprises in Malaysia. Business Strategy Series, Vol. 11 pp.75-77, https://doi.org/10.1108/17515631011026371.

Franco, M., \& Haase, H. (2013). Firm resources and entrepreneurial orientation as determinants for collaborative entrepreneurship. Management Decision, Vol. 51 Issue: 3, pp.680-696, https://doi.org/10.1108/00251741311309724.

Grinstein, A. (2008). The relationships between market orientation and alternative strategic orientations: A meta-analysis. European Journal of Marketing, Vol. 42 Issue: 1/2, pp.115-134 https://doi.org/10.1108/03090560810840934.

Gupta, V. K. (2015). New England Journal of Entrepreneurship. Construction of entrepreneurial orientation: Dispute, demand, and dare, Vol. 18 Issue: 1, pp.87-89.

Jia, J., Wang, G., Zhao, X., \& Yu, X. (2014). Exploring the relationship between entrepreneurial orientation and corporate performance: The role of competency of executives in entrepreneurial oriented corporations. Nankai Business Review International, Vol. 5 Issue: 3, pp.326-344, https://doi.org/10.1108/NBRI-05-2014-0024. 
Kajalo, S., \& Lindblom, A. (2015). Market orientation, entrepreneurial orientation and business performance among small retailers. International Journal of Retail \& Distribution Management, Vol. 43 Issue: 7, pp.580-596, https://doi.org/10.1108/IJRDM-04-2014-0044.

Khalili, H., Nejadhussein, S., \& Fazel, A. (2013). The influence of entrepreneurial orientation on innovative performance: Study of a petrochemical company in Iran. Journal of Knowledge-based Innovation in China, Vol. 5 Issue: 3, pp.262-278, https://doi.org/10.1108/JKIC-09-2013-0017.

Kocak, A., Carsrud, A., \& Oflazoglu, S. (2017). Market, entrepreneurial, and technology orientations: impact on innovation and firm performance. Management Decision, Vol. 55 Issue: 2,pp.248-270, https://doi.org/10.1108/MD-04-2015-0146.

Lan, Q., \& Wu, S. (2010). An empirical study of entrepreneurial orientation and degree of internationalization of small and mediumsized Chinese manufacturing enterprises. Journal of Chinese Entrepreneurship, Vol. 2 Issue: 1, pp.53-75, https://doi.org/10.1108/17561391011019023.

Lee, J., \& Roh, J. J. (2012). Revisiting corporate reputation and firm performance link. Benchmarking: An International Journal, Vol. 19 Issue: 4/5, pp.649-664, https://doi.org/10.1108/14635771211258061.

Lee, T., \& Chu, W. (2017). The relationship between entrepreneurial orientation and firm performance: Influence of family governance. Journal of Family Business Strategy, Journal of Family Business Strategy 8 (2017) 213-223.

Li, Y. H., Huang, J. W., \& Tsai, M. T. (2009). Entrepreneurial orientation and firm performance: The role of knowledge creation process. Industrial Marketing Management, Industrial Marketing Management 38 (2009) 440-449.

Lindorff, M., \& Jonson, E. P. (2013). CEO business education and firm financial performance: a case for humility rather than hubris. Education + Training, Vol. 55 Issue: 4/5, pp.461-477 https://doi.org/10.1108/00400911311326072.

Liu, H., Ke, W., Wei, K. K., \& Hua, Z. (2013). Effects of supply chain integration and market orientation on firm performance: Evidence from China. International Journal of Operations \& Production 
Management, Vol. 33 Issue: 3, pp.322-346, https://doi.org/10.1108/01443571311300809.

Madanoglua, M., Kizildagb, M., \& Ozdemir, O. (2018). Which bundles of corporate governance provisions lead to high firm performance among restaurant firms? International Journal of Hospitality Management , 98-108.

Mahrous, A. A., \& Genedy, M. A. (2018). Connecting the dots: The relationship among intra-organizational environment, entrepreneurial orientation, market orientation and organizational performance. Journal of Entrepreneurship in Emerging Economies, https://doi.org/10.1108/JEEE-09-2016-0036.

Matear, S., Osborne, P., Garrett, T., \& Gray, B. J. (2002). How does market orientation contribute to service firm performance?: An examination of alternative mechanisms. European Journal of Marketing, Vol. 36 Issue: 9/10, pp.1058-1075, https://doi.org/10.1108/03090560210437334.

Montiel-Campos, ,. H. (2018). Entrepreneurial orientation and market orientation: Systematic literature review and future research. Journal of Research in Marketing and Entrepreneurship , Vol 20 Issue: 2, pp.292-322, https://doi.org/10.1108/JRME-09-2017-0040.

Morgan, T., Anokhin, S., \& Wincent, J. (2016). Entrepreneurial orientation, firm market power and opportunism in networks. Journal of Business \& Industrial Marketing , Vol. 31 Issue: 1, pp.99-111, https://doi.org/10.1108/JBIM-03-2014-0063.

Muecke, T. G., \& Hofer, K. M. (2015). Market orientation, entrepreneurial orientation and performance in emerging markets. International Journal of Emerging Markets, Vol. 10 Issue: 3, pp.560571, https://doi.org/10.1108/IJoEM-05-2013-0076.

Ngai, J. C., \& Ellis, P. (1998). Market orientation and business performance: some evidence from Hong Kong. International Marketing Review, Vol. 15 Issue: 2, pp.119-139, https://doi.org/10.1108/02651339810212502.

Othman, A. A., Rahman, S. A., Sundram, V. P., \& Bhatti, M. A. (2015). Modelling marketing resources, procurement process coordination and firm performance in the Malaysian building construction industry. 
Engineering, Construction and Architectural Management, Vol. 22 Issue: 6, pp.644-668, https://doi.org/10.1108/ECAM-02-2014-0030.

Pehrsson, A. (2016). Firm's strategic orientation, market context, and performance: Literature review and opportunities for international strategy research. European Business Review, Vol. 28, Issue: 4, pp.378404, https://doi.org/10.1108/EBR-11-2015-0142.

Pratono, A.H. (2016). Strategic orientation and information technological turbulence: Contingency perspective in SMEs, Business Process Management Journal, Vol 22, Issue: 2, pp.368-382, https://doi.org/10.1108/BPMJ-05-2015-0066

Pratono, A. H., Ratih, R. V., \& Arshad, D. (2018). Does Entrepreneurial Autonomy Foster SME Growth Under Technological Turbulence? The Empirical Evidence from Indonesia. Journal of Technology in Behavioral Science 3, pp. 170. https://doi.org/10.1007/s41347-018-0051-9

Pratono, A. H. (2018). Does firm performance increase with risk-taking behavior under information technological turbulence? Empirical evidence from Indonesian SMEs, The Journal of Risk Finance, doi: 10.1108/JRF-10-2017-0170.

Rezaei, J., \& Ortt, R. (2018). Entrepreneurial orientation and firm performance: the mediating role of functional performances. Management Research Review , Vol. 41 Issue: 7, pp.878-900 https://doi.org/10.1108/MRR-03-2017-0092.

Shan, P., Song, M., \& Ju, X. (2016). Entrepreneurial orientation and performance: Is innovation speed a missing link? Journal of Business Research , Journal of Business Research 69 (2016) 683-690.

Shirokova, G., Bogatyreva, K., \& Belia, T. (2016). Entrepreneurial orientation and firm performance in different environmental settings: Contingency and configurational approaches. Journal of Small Business and Enterprise Development , Vol. 23 Issue: 3, pp.703-727 https://doi.org/10.1108/JSBED-09-2015-0132.

Shoham, A., Rose, G. M., \& Kropp, F. (2005). Market orientation and performance: a meta-analysis. Marketing Intelligence \& Planning, Vol. 23 Issue: 5, pp.435-454, https://doi.org/10.1108/02634500510612627. 
Tarus, D. K., \& Aime, F. (2014). Board demographic diversity, firm performance and strategic change: A test of moderation. Management Research Review, Vol. 37 Issue: 12, pp.1110-1136

https://doi.org/10.1108/MRR-03-2013-0056.

Todorovic, Z. W., \& Ma, J. (2008). Entrepreneurial and market orientation relationship to performance: The multicultural perspective. Journal of Enterprising Communities: People and Places in the Global Economy, Vol. 2 Issue: 1, pp.21-36.

Tseng, P.-H., \& Liao, C.-H. (2015). Supply chain integration, information technology, market orientation and firm performance in container shipping firms. The International Journal of Logistics Management, Vol. 26 Issue: 1, pp.82-106, https://doi.org/10.1108/IJLM-09-2012-0088.

Vora, D., Vora, J., \& Polley, D. (2012). Applying entrepreneurial orientation to a medium sized firm. International Journal of Entrepreneurial Behavior \& Research , Vol. 18 Issue: 3, pp.352-379, https://doi.org/10.1108/13552551211227738.

Wolff, J. A., Pett, T. L., \& Ring, J. K. (2015). Small firm growth as a function of both learning orientation and entrepreneurial orientation: An empirical analysis. International Journal of Entrepreneurial Behavior \& Research , Vol. 21 Issue: 5, pp.709-730, https://doi.org/10.1108/IJEBR-12-2014-0221.

Wong, S. K.-S. (2014). Impacts of environmental turbulence on entrepreneurial orientation and new product success. European Journal of Innovation Management, Vol. 17 Issue: 2, pp.229-249 https://doi.org/10.1108/EJIM-04-2013-0032.

Zehir, C., Can, E., \& Karaboga, T. (2015). Linking entrepreneurial orientation to firm performance: the role of differentiation strategy and innovation performance. 4th International Conference on Leadership, Technology, Innovation and Business Management, Procedia - Social and Behavioral Sciences 210 ( 2015 ) 358- 367. 